\title{
Introducing a New Method to Increase Critical Clearing Time (CCT) and Improve Transient Stability of Synchronous Generator Using Brake Resistance
}

Ebadollah Amouzad Mahdiraji ${ }^{*}$, (D)

${ }^{a, *}$ Sari Branch, Islamic Azad University, Department of Engineering, Sari, IRAN

\begin{tabular}{l} 
ARTICLE \\
INFO \\
\hline Received: 08.04 .2020 \\
Accepted: 12.07 .2020 \\
\hline Keywords: \\
Dynamic Brake \\
Resistance, Transient \\
Stability, Oscillation \\
Damping, Critical \\
Clearing Time \\
*Corresponding \\
Authors \\
e-mail: \\
ebad.amouzad@gmail.
\end{tabular}

\begin{abstract}
In general, the sustainability of power systems can be considered as a feature of the system that enables it to remain in equilibrium under normal conditions and regain a different acceptable state if it is affected by turbulence. Instability in a power system can take many forms, depending on the composition of the system and its operating conditions. In this study, a new method is applied to reduce transient fluctuations and network instability. Due to the aim of the study is transient stability, modelling of thermal resistance in transient stability it was introduced in some part of the article. After, In the other part of the brake resistance control, the brake resistance control was used by a switched Thyristor, the corresponding mathematical relations using the trapezoidal method. The obtained simulation results were presented with the presence of TCBR and its ability to embed in the desired network.
\end{abstract}

https://dx.doi.org/10.30855/gmbd.2020.02.06

com

\section{Senkron Jeneratörün Geçici Kararlılığını ve Kritik Temizleme Süresini} (CCT) Artırmak için Fren Direnci Kullanımı ile Yeni Bir Yaklaşımın Sunumu

\section{MAKALE \\ BİLGISİ \\ Alınma: 08.04.2020 \\ Kabul: 12.07 .2020 \\ Anahtar Kelimeler: \\ Dinamik Fren Direnci, \\ Geçici Kararlılık, \\ Salınım Sönümleme, \\ Kritik Temizleme \\ Süresi \\ "Sorumlu Yazar: \\ e-posta: \\ ebad.amouzad@gmail. \\ com}

\section{ÖZ}

Genel olarak güç sistemlerinin sürdürülebilirliği, sistemin normal şartlarda dengede kalmasını, türbülanstan etkilenmesi durumunda ise farklı bir duruma gelmesini sağlayan özellik olarak düşünülebilir. Güç sistemindeki kayıplar, sistemin yapısına ve çalışma koşullarına bağlı olarak birçok şekilde olabilir. Bu çalışmada, geçici dalgalanmaları ve ağ istikrarsızlığını azaltmak için yeni bir yöntem uygulanmıştır. Çalışmanın amacı geçici kararlılık olduğundan, geçici kararlılıkta termal direncin modellenmesi makalenin bir bölümünde tanıtılmıştır. Ardından, trapezoidal yöntem kullanılarak fren direnci kontrolüne karşılık gelen matematiksel eşitliğe sahip anahtarlı bir Tristör kullanılmıştır. Elde edilen simülasyon sonuçları, TCBR'nin varlığı ve istenen ağa gömülebilme yeteneği ile sunulmuştur.

https://dx.doi.org/10.30855/gmbd.2020.02.06

Bu makaleye atıf yapmak için: E.A. Mahdiraji, "Introducing a New Method to Increase Critical Clearing Time (CCT) and Improve Transient Stability of Synchronous Generator Using Brake Resistance," Gazi Journal of Engineering Sciences, vol. 6, no. 2, pp. 138-144, August, 2020, doi: https://dx.doi.org/10.30855/gmbd.2020.02.06. 


\section{INTRODUCTION}

In recent years, the use of FACTs as controllable components has increased the capacity of existing transmission lines, thus avoiding or at least delaying the need to install new lines that are often confined to economic and environmental reasons. In addition to increasing the capacity of the transmission system, the complementary controls added to these FACTs equipment attenuates inter-region fluctuations [1-4]. Although power system stabilizers have been widely used to provide additional attenuation in inter-region oscillations of the power system, the potential of complementary damping controllers in FACTs devices has been confirmed then the power system stabilizers [5].

Modern power systems are large and complex systems that are exploited under economic pressures in a restructured competitive environment. These pressures cause the power system to operate under conditions very close to the security limits. Limits that may not be well-identified. During normal operation of the power system, there is a balance between the mechanical power input to each power plant unit and the output electrical power plus loss. The problem arises when a sudden disturbance causes changes in the output of electrical power. These disorders can include events such as the occurrence of short circuits on lines or generator-connected chains. The magnitude of the disturbance is determined by the output power loss and sudden acceleration. Brake resistor is a high energy loss resistor in a short period that rapidly enters the circuit at the time of the fault such as a resistor load and absorbs accelerator energy generated by the fault and increases power consumption.

Reference [6] employs an approach based on the use of FACTS devices to improve the stability of power systems. For this purpose, using a conventional controller and a fuzzy logic controller based on braking resistance, the transient stability improvement of a synchronous generator in a single machine and then a multi-machine is investigated.

In reference [7], a two-layer control structure, designated as a Thyristor-controlled braking resistor (BR) control system, is proposed for the operation of a multi-machine power system in transient conditions. In this method, multiple local physical controllers are introduced in the network load settings and power transfer modes after a severe disturbance on the rotor angle and rotor speed of each generator and the firing angle of each Thyristor controls the time and amount of BR. For the introduced case, the damping is increased and the stability margin is increased. The results obtained in this method show that the controller is capable of controlling the system when instability conditions are occurring.

In [8], two different new brake models are presented, one involving a Thyristor rectifier and the other involving a combination of a diode rectifier and a cutter whose performance is compared to the current Thyristor controlled brake resistor. In this comparison, an index of speed performance of the number of components used, heat loss and harmonics simulation for each model is presented and the final model is introduced. The effectiveness of the proposed method has been tested through Matlab/Simulink simulation concerning unbalanced and temporal errors in the power system.

Reference [9], using Thyristor-controlled braking resistor and fuzzy logic, has been used to increase transient stability in a multi-machine power system. In this method, the time derivative of total kinetic energy deviation is used as a fuzzy controlled input for braking resistance switching. It is noted in this paper that the time derivative function as a controller input, to reduce installation costs as well as the computational burden, reduces the use of brake resistor numbers in appropriate locations rather than installing any braking resistor. The bus terminal becomes each generator.

Reference [10-13], two brake resistor models, one consisting of a Thyristor rectifier and the other consisting of a combination of a diode rectifier and a system breaker, are presented. In this case, their performance is compared with the existing braking resistance.

Reference [14-18] has been used to model and adjust the hydro turbine governor and design of dynamic braking resistors to improve transient stability in the generator. In this reference, the dynamic braking resistance proposed by the combination of the existing governor regulator is used to improve the stability of the generator stability margin as a transient stability criterion. The simulation results show that the proposed method to avoid generator speeds exceeding the limit when a severe fault occurs in the power system can be avoided by removing all or part of the load.

\section{INTRODUCE THE PROPOSED NETWORK WITH TCBR PRESENCE}

Brake resistance is a resistor that can be cut and connected with a Thyristor and its effective amount in 
the circuit can be changed. To investigate the presence of TCBR in the power grid, a typical grid is introduced as in Figure (1). The target network is an infinite single-machine network, which is intended to investigate the presence of TCBR in the network. In the presented network, it is assumed that the TCBR is mounted on the generator bus to aid in the attenuation of possible fluctuations. An overview of the network studied is shown in Figure (1).

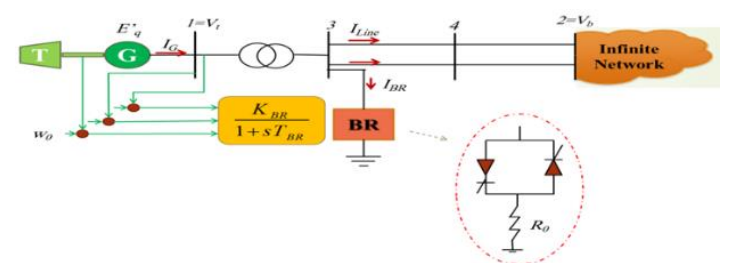

Figure 1. The studied network in the presence of TCBR

In order to evaluate the proposed method for mitigating transient fluctuations and network stability, a study is conducted on a specific network in this section. The proposed flowchart is presented in Figure (2).

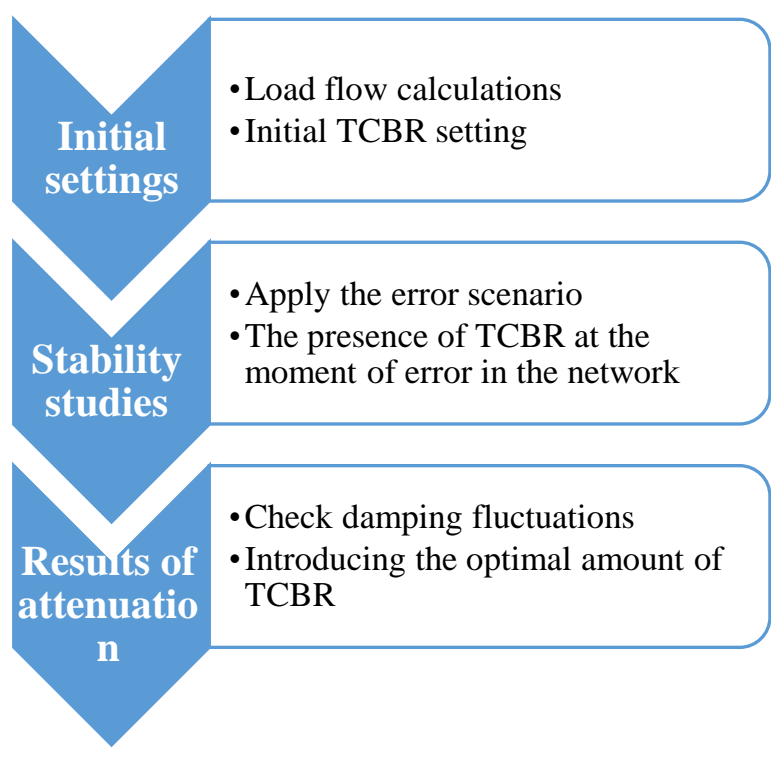

Figure 2. Flowchart of the proposed method

\section{BRAKING RESISTANCE MODELLING IN TRANSIENT STABILITY}

The braking resistance modelling process is introduced to investigate the transient stability of the introduced equations. Consider the network order shown in Figure 3. In TCBR we have a brake resistor whose current is cut off and connected according to the angle of fire, in this section we want to find an equivalent braking resistor related to the angle of fire that has a continuous current. As mentioned, the flow form will be sinusoidal so that the maximum value of the new wave is less than the maximum of the previous discrete current.

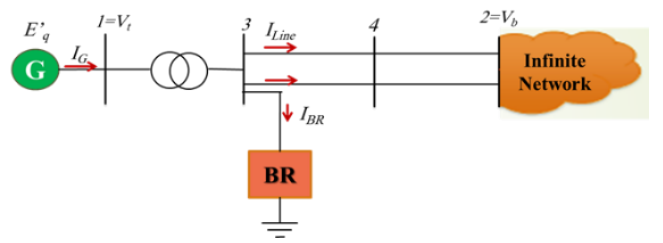

Figure 3. The target network with the presence of TCBR to study the transient stability

In accordance with figure (2) we have:

$$
\begin{gathered}
I L=\text { Iline } \\
I B R=\text { IBreaking Rsisto }
\end{gathered}
$$

Network admittance matrix of the single machine connected to an infinite bus are:

$$
I_{B u s}=Y_{B u s} V+G_{B R} U_{k} V
$$

$\left[\begin{array}{c}I_{G b} \\ 0\end{array}\right]=\left[\begin{array}{ll}Y_{11} & Y_{12} \\ Y_{21} & Y_{22}\end{array}\right]\left[\begin{array}{c}V_{t b} \\ V_{34}\end{array}\right]+G_{B R}\left[\begin{array}{cc}U_{k 1} & 0 \\ 0 & U_{k 2}\end{array}\right]\left[\begin{array}{l}V_{t b} \\ V_{34}\end{array}\right]$

Depending on the network we have:

$U_{k 1}=\left[\begin{array}{ll}0 & 0 \\ 0 & 0\end{array}\right] \quad, \quad U_{k 2}=\left[\begin{array}{ll}1 & 0 \\ 0 & 0\end{array}\right]$

Reduced network admissions matrix:

$\left\{I_{G b}=Y_{11} V_{t b}+Y_{12} V_{34}+G_{B R} U_{k 1} V_{t b}\right.$

$\left\{0=Y_{21} V_{t b}+Y_{22} V_{34}+G_{B R} U_{k 2} V_{34}\right.$

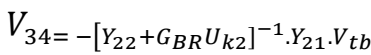

$=\left(Y_{11}+G_{B R} U_{k 1}\right) \cdot V_{t b}-Y_{12} \cdot\left[Y_{22}+\right.$

$\left.G_{B R} U_{k 2}\right]^{-1} \cdot Y_{21} \cdot V_{t b}$

$I_{G b}=\left[Y_{11}+G_{B R} U_{k 1}\right)-Y_{12} \cdot\left[Y_{22}+\right.$

$\left.\left.G_{B R} U_{k 2}\right]^{-1} \cdot Y_{21}\right] \cdot V_{t b}$

$I_{G b}=\left[Y_{11}-Y_{12} \cdot\left[Y_{22}+G_{B R} U_{k 2}\right]^{-1} \cdot Y_{21}\right] \cdot V_{t b}$

$I_{G b}=$

$Y_{R} \cdot V_{t b}$ 


$$
\begin{aligned}
& {\left[\begin{array}{l}
I_{G} \\
I_{b}
\end{array}\right]=} \\
& {\left[\begin{array}{ll}
Y_{R 1} & Y_{R 2} \\
Y_{R 3} & Y_{R 4}
\end{array}\right]\left[\begin{array}{l}
V_{t} \\
V_{b}
\end{array}\right]} \\
& I_{G}=Y_{R 1} V_{t}+ \\
& Y_{R 2} V_{b} \\
& I_{d}+j I_{q}=\left(G_{R 1}+j B_{R 1}\right)\left(V_{d}+j V_{q}\right)+\left(G_{R 2}+\right. \\
& \left.j B_{R 2}\right)\left(V_{b d}+j V_{b q}\right) \\
& \left\{\begin{array}{l}
I_{d}=G_{R 1} V_{d}-B_{R 1} V_{q}+G_{R 2} V_{b d}-B_{R 2} V_{b q} \\
I_{q}=G_{R 1} V_{q}+B_{R 1} V_{d}+G_{R 2} V_{b q}+B_{R 2} V_{b d}
\end{array}\right.
\end{aligned}
$$

Finally, the matrix form of the equations is:

$$
\begin{gathered}
{\left[\begin{array}{l}
I_{d} \\
I_{q}
\end{array}\right]=\underbrace{\left[\begin{array}{cc}
G_{R 1} & -B_{R 1} \\
B_{R 1} & G_{R 1}
\end{array}\right]\left[\begin{array}{l}
V_{d} \\
V_{q}
\end{array}\right]}_{G B R 1}+\underbrace{\left[\begin{array}{cc}
G_{R 2} & -B_{R 2} \\
B_{R 2} & G_{R 2}
\end{array}\right]\left[\begin{array}{c}
V_{b d} \\
V_{b q}
\end{array}\right](16)}_{G B R 2}} \\
I_{d q}=G B R 1 . V_{d q}+G B R 2 . V_{b d q}
\end{gathered}
$$

Generator equations:

$\left\{\begin{array}{l}V_{d}=X_{q} I_{q} \\ V_{q}=E_{q}^{\prime}-X_{d}^{\prime} I_{d}\end{array}\right.$

Matrix Form of Generator Equations:

$$
\begin{gathered}
\underbrace{\left[\begin{array}{l}
V_{d} \\
V_{q}
\end{array}\right]=\left[\begin{array}{cc}
0 & X_{q} \\
-X_{d}^{\prime} & 0
\end{array}\right]}_{X D Q} \underbrace{\left[\begin{array}{l}
I_{d} \\
I_{q}
\end{array}\right]+\left[\begin{array}{l}
0 \\
1
\end{array}\right]}_{U} E_{q}^{\prime} \\
V_{d q}=X D Q \cdot I_{d q}+U \cdot E_{q}^{\prime}
\end{gathered}
$$

By pasting in the $\mathrm{I}_{\mathrm{dq}}$ relation we have:

$$
\begin{gathered}
I_{d q}=[G B R 1] \cdot\left(X D Q \cdot I_{d q}+U \cdot E_{q}^{\prime}\right)+[G B R 2] \cdot V_{b d q} \\
{[I-G B R 1 . X D Q] \cdot I_{d q}=G B R 1 \cdot U \cdot E_{q}^{\prime}+G B R 2 . V_{b d q}}
\end{gathered}
$$

$$
\begin{aligned}
& I_{d q}=[\underbrace{I-G B R 1 .]^{-1} \cdot G B R 1 \cdot U \cdot E_{q}^{\prime}}_{Y H}+[\underbrace{I-G B R 1 . X D Q]^{-1} G B R 2}_{Y E} . \\
& V_{b d q}=\left[\begin{array}{l}
V_{b} \sin \delta \\
V_{b} \cos \delta
\end{array}\right]
\end{aligned}
$$$$
I_{d q}=[Y E] \cdot E_{q}^{\prime}+[Y H] \cdot V_{b d q}
$$$$
V_{d q}=X D Q \cdot I_{d q}+E_{q}^{\prime}
$$

By embedding the $\mathrm{I}_{\mathrm{dq}}$ relationship we will have:

$$
V_{d q}=U \cdot E_{q}^{\prime}+X D Q \cdot\left[E \cdot E_{q}^{\prime}+H \cdot V_{b d q}\right]
$$

$$
\begin{gathered}
V_{d q}=U \cdot E_{q}^{\prime}+[X D Q \cdot E] \cdot E_{q}^{\prime}+[X D Q \cdot H] \cdot V_{b d g} \\
V_{d q}=\underbrace{[U+X D Q \cdot E] \cdot E_{q}^{\prime}}_{Y L}+\underbrace{[X D Q \cdot H] \cdot V_{b d q}}_{Y N} \\
V_{d q}=[Y L] \cdot E_{q}^{\prime}+[Y N] \cdot V_{b d q}
\end{gathered}
$$

\section{SIMULATION OUTPUT ANALYSIS ON THE SAMPLE NETWORK}

In this section, a short circuit fault scenario is applied to the desired grid under the presented relationships and the ability of TCBR to dampen the oscillations of the synchronous generator is investigated. The parameters of the generator and transmission lines are considered by Table (1) and (2). Also, the information obtained from system load propagation studies is provided in Table (3) to obtain the starting point of the system.

Table 1. Generator parameter values and AVR control coefficients

\begin{tabular}{|c|c|c|}
\hline \multicolumn{3}{|c|}{ Generator's Parameters } \\
\hline $\mathrm{X}_{\mathrm{d}}$ & Steady state direct-axis reactance & 1.2 \\
\hline $\mathrm{X}_{\mathrm{q}}$ & Steady state quadrature reactance & 0.8 \\
\hline $\mathrm{X}_{\mathrm{pd}}$ & Transient direct-axis reactance & 0.2 \\
\hline $\mathrm{H}$ & Inertia Constant & 5 \\
\hline $\mathrm{T}_{\mathrm{pdo}}$ & Direct-axis transient short-circuit time constant & 7 \\
\hline $\mathrm{KA}$ & AVR gain & 100 \\
\hline $\mathrm{TA}$ & AVR time constant & 1 \\
\hline $\mathrm{f}_{0}$ & System frequency & 50 \\
\hline
\end{tabular}

Table 2. Reactance values of line and transformer parameters

\begin{tabular}{|c|c|c|}
\hline \multicolumn{3}{|c|}{ Network and Transformer's Parameters } \\
\hline $\mathrm{Xl}_{1}$ & Line reactance & 0.2 \\
\hline $\mathrm{Xl}_{2}$ & Line reactance & 0.2 \\
\hline $\mathrm{Xl}_{3}$ & Line reactance & 0.2 \\
\hline $\mathrm{Xl}_{4}$ & Line reactance & 0.2 \\
\hline $\mathrm{X}_{\mathrm{t}}$ & Transformer reactance & 0.1 \\
\hline
\end{tabular}

Table 3. Quantities obtained from load flow studies

\begin{tabular}{|r|c|c|}
\hline \multicolumn{3}{|c|}{ Load Flow Analysis } \\
\hline $\mathrm{V}_{\mathrm{t}}$ & Terminal voltage & 1.05 \\
\hline $2 \mathrm{~B}_{\mathrm{e}}{ }^{2}$ & Real power output of the machine & 0.8 \\
\hline $\mathrm{Q}_{\mathrm{e} 0}$ & Reactive power output of the machine & 0.6 \\
\hline $\mathrm{W}_{0}$ & Rated angular velocity & 314.15927 \\
\hline
\end{tabular}

As shown in Figure (3), it is assumed that a short circuit error on terminal 3 will somehow fluctuate for the generator fault. By the relationships introduced in this section, the TCBR control model is coded in the MATLAB software space. According to the program presented below, the generator angle and velocity fluctuations in the presence and absence of TCBR are presented. An overview of the generator angle and velocity fluctuations in exchange for the presence or absence of TCBR is given in Figures (4) to (7). 
According to Figures (4) and (5), it is observed that in the absence of TCBR and with increasing time, angle and velocity both decrease and become unstable. Also in Figures (6) and (7), it is observed that in the presence of TCBR, as the time, angle and velocity decrease favourably. This section illustrates the ability of TCBR to dampen fluctuations. The results of the above simulations show that if the TCBR is used at the right time and optimally, the rotor angle fluctuations of the generators will be attenuated appropriately. It can be seen in this section that using a control element in the network can help attenuate the damping of the network.

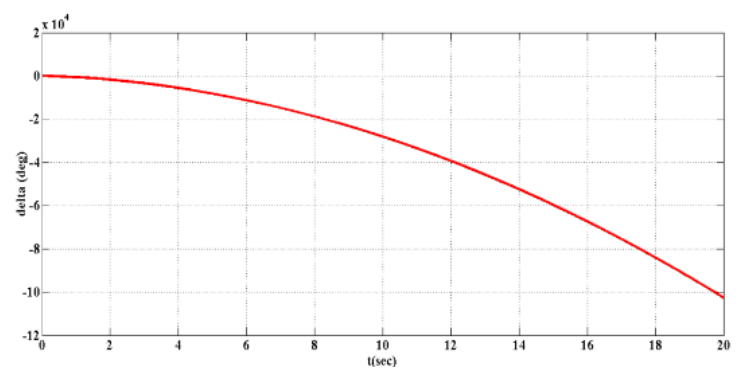

Figure 4. Generator angle oscillation without the presence of TCBR

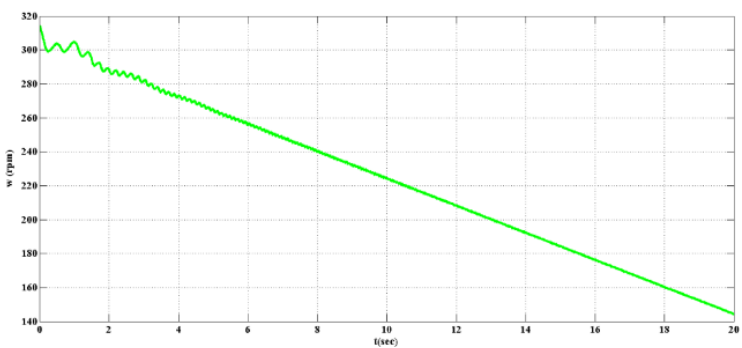

Figure 5. Generator speed oscillation without the presence of TCBR

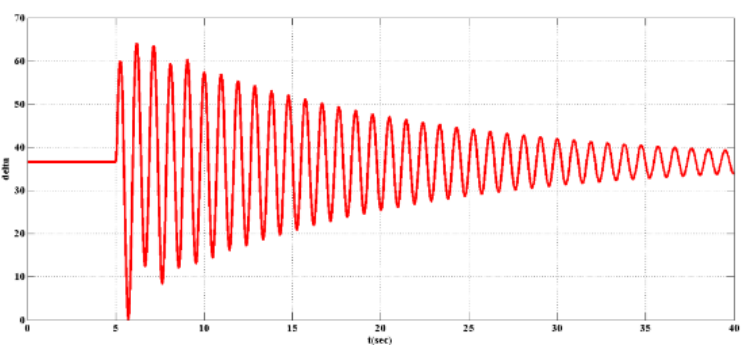

Figure 6. Generator angle oscillations in the presence of TCBR

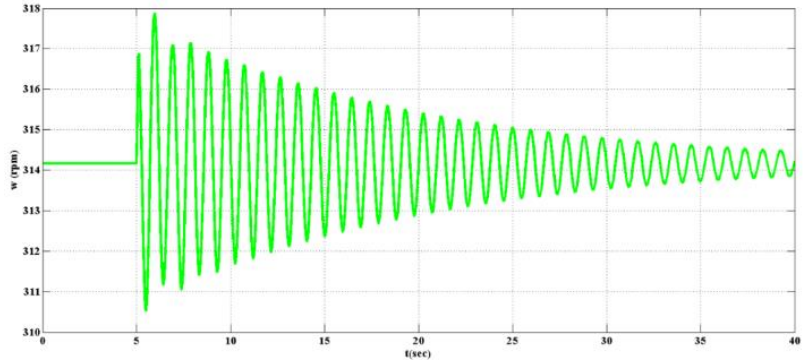

Figure 7. Generator speed oscillations in the presence of TCBR

\section{CONCLUSION}

In this paper, while introducing the different capabilities and applications of FACTS equipment in different areas, the proposed solution to reduce losses is to use FACTS controllers. Among these devices, one focuses on a power flow controller called Dynamic Brake Resistance (TCBR) and its purpose is to investigate its impact and adjustment for transient network stability. To investigate the impact of TCBR on transient stability studies, a suitable mathematical model has been described and an appropriate power injection model has been demonstrated to demonstrate its playability. The introduction of the TCBR model into the network understudy to perform optimum broadcast computation by MATLAB software was done by adding a virtual bus to the network. This virtual bus, which we consider nb+1, was added to the Toolbox and the network equipped with this equipment was compared to TCBR-free. The analysis of the results shows that by adding a TCBR number to the studied network, the unstable fluctuations in the network have been desperately attenuated. In this regard, the most suitable location for IPC installation is to increase the attenuation of the system in the generator bus. The main advantages of the proposed method over the previous methods can be summarized in the simplicity of problem analysis and its formulation, satisfying all constraints of equality and inequality in achieving the optimal work point. Comparison of the proposed method with the work done in the field shows that, unlike previous methods, TCBR as a cheaper FACTS controller has increased network stability to a greater extent; At the same time, it offers other capabilities such as fault current limiting, independent control of active and reactive power, thereby increasing system flexibility.

\section{CONFLICTS OF INTEREST}

No conflict of interest was declared by the author. 


\section{REFERENCES}

[1] M. Saeedifard, M. Graovac, R.F. Dias, R. "Iravani, DC power systems: Challenges and opportunities," in Power and Energy Society General Meeting, IEEE 1-7, 2010.

[2] X. Yang, Z. Lin, Q. Zheng Trillion, "A Review of Modular Multilevel Converters," Proceedings of the CSEE, vol. 33, no. 6, pp. 1-14, 2013.

[3] M. Klein, G.J. Rogers, P. Kundur, "A fundamental study of inter-area oscillations in power systems," IEEE Trans. Power Syst., vol. 6, no. 3, pp. 914-921, August,1991, doi: $10.1109 / 59.119229$.

[4] X. Shiyun, W. Ping, B. Zhao, "Coordinated Control Strategy of Interconnected Grid Integrated With UHVDC Transmission Line From Hami to Zhengzhou," Power Sys-tem Technology, vol. 39, no. 7, pp. 1773-1778, 2015.

[5] J. Dorn, H. Huang, D. Retzmann, "Novel Voltage-Sourced Converters for HVDC and FACTS Applications," in Cigr'e Symposium Osaka, November, 2007, Osaka, Japan [Online]. Available: Cinii, https://ci.nii.ac.jp/naid/10021134894/. [Accessed: 9 Sept. 2019].

[6] S. Chatzivasileiadis, D. Ernst, G. Andersson, "The Global Grid," Renewable Energy, vol. 57, no. 1, pp. 372-383, 2013.

[7] M.E. Aboul-Ela, A.A. Sallam, J.D. McCalley, A.A. "Fouad, Damping controller design for power system oscillations using global signals," Power Syst. IEEE Trans, vol. 11, no. 2, pp. 767-773, May, 1996, doi: 10.1109/59.496152.

[8] Y. Li, C. Rehtanz, S. Ruberg, L. Luo, Y. Cao, "Wide-area robust coordination approach of HVDC and FACTS controllers for damping multiple interarea oscillations," IEEE Transactions on Power Delivery, vol. 27, no. 1, pp. 1096-1105, July, 2012, doi: 10.1109/TPWRD.2012.2190830.

[9] P. McNamara, R.R. Negenborn, B. De Schutter, G. Lightbody, "Optimal coordination of a multiple HVDC link system using centralized and distributed control," Control Syst. Technol. IEEE Trans, vol. 21, no. 2, pp. 302-314, March, 2012, doi: 10.1109/TCST.2011.2180906.
[10] L. Papangelis, M.S. Debry, P. Panciatici, T. Van Cutsem,"Coordinated supervisory control of multi-terminal HVDC grids: a model predictive control approach", IEEE Transactions on Power Systems, Vol. 32, no. 6, pp. 4673-4683, November, 2017, doi: 10.1109/TPWRS.2017.2659781.

[11] G. Hug-Glanzmann, "Coordinated power flow control to enhance steady-state security in power systems, Ph.D. dissertation", Dept. Inf. Technol. Elect. Eng., ETH Zurich, Zurich, Switzerland, Diss. ETH No. 17586.

[12] Z. Wan, M.V. Kothare, "An efficient off-line formulation of robust model predictive control using linear matrix inequalities," Automatica, vol. 39, no. 5, pp. 837-846, February, 2003, doi: https://doi.org/10.1016/S0005-1098(02)00174-7.

[13] M.V. Kothare, V. Balakrishnan, M. Morari, "Robust constrained model predictive control using linear matrix inequalities," Automatica, vol. 32, no. 10, pp. 1361-1379, October, 1996, doi: https://doi.org/10.1016/0005-1098(96)00063-5.

[14] J. Liu, D. Muñoz de la Peña, P.D. "Christofides, J.F. Davis, Lyapunov-based model predictive control of nonlinear systems subject to time-varying measurement delays," Int. J. Adapt. Control Signal Process, vol. 23, no. 8, pp. 788807, November, 2009, doi: https://doi.org/10.1002/acs.1085.

[15] B. Boukhezzar, H. Siguerdidjane, "Nonlinear control with wind estimationof a dfig variable speed wind turbine for power capture optimization," Energy Conversion and Management, vol. 50, no. 4, pp. 885-892, April, 2009, doi: https://doi.org/10.1016/j.enconman.2009.01.011.

[16] M. Mahmood, P. Mhaskar, "Lyapunovbased model predictive control of stochastic nonlinear systems," Automatica, vol. 48, no. 9, pp. 2271-2276, September, 2012, doi: https://doi.org/10.1016/j.automatica.2012.06.033.

[17] M. Li, W. Huang, N. Tai, M. Yu, "LyapunovBased Large Signal Stability Assessment for VSG Controlled Inverter-Interfaced Distributed," Generators, vol. 11, no 9, pp. 1-15, August, 2018, doi: https://doi.org/10.3390/en11092273.

[18] M.P. Akter, S. Mekhilef, N.M.L. Tan, H. Akagi, "Modified model predictive control of a 
bidirectional AC-DC converter based on Lyapunov function for energy storage systems," IEEE Trans. Ind. Electron, vol. 63, no. 2, pp. 704715, February, 2016, doi: 10.1109/TIE.2015.2478752

\section{Ebadollah Amouzad MAHDIRAJI}

Ebadollah Amouzad Mahdirji completed his bachelor's and master's degrees in power electrical engineering at Sari Branch of the Islamic Azad University in 2013 and 2015. Respectively, he is currently a researcher in the field of energy and power systems. His research areas of interest include transient's analysis in electrical equipment, optimization, and operation of smart grids. 